\title{
SECOND BRANCHIAL CYST: A RARE PRESENTATION
}

\author{
G. Vinod Kumar ${ }^{1}$, B. Ranganatha Reddy², Supriya Mohan Bhat ${ }^{3}$, Rakesh Vuppala ${ }^{4}$
}

\section{HOW TO CITE THIS ARTICLE:}

G. Vinod Kumar, B. Ranganatha Reddy, Supriya Mohan Bhat, Rakesh Vuppala. "Second Branchial Cyst: A Rare Presentation". Journal of Evolution of Medical and Dental Sciences 2015; Vol. 4, Issue 73, September 10;

Page: 12793-12795, DOI: $10.14260 /$ jemds/2015/1842

ABSTRACT: Branchial cysts are uncommon but a known reason of swelling in the neck. They lie deep to the sternocleidomastoid muscle and present in the anterior triangle of the neck. These cysts are usually seen in young adults. We report a case of Branchial cyst in a 60 year old female presenting with a painless swelling on the right side of the neck.

KEYWORDS: Branchial cyst, Cystic lesions of neck, Late presentation of branchial cyst, Cervical cyst.

INTRODUCTION: Branchial cysts are the most frequent cysts in the neck. Among the branchial anomalies, second branchial cleft anomalies are most common, representing approximately 95\% of cases.[1,2] Branchial cysts equally occur in both sexes and peak incidence is in the third decade. ${ }^{[3,4]}$

CASE REPORT: 60 years old female presented to ENT OPD with complains of swelling over the right side of the neck for the past 3 years. It was insidious in onset, gradually progressive in size. On examination there was a swelling in the right side of the neck which was approximately $5.5 \mathrm{x} 4 \mathrm{~cm}$ in size, oval in shape, not moving with deglutition. No visible pulsations were seen over the swelling. On palpation there was a single, soft, cystic swelling over the right side of the neck, which was nontender, not moving vertically as well as horizontally, no other clinically palpable nodes. Trachea deviated to left side.

Ultrasonography of the neck showed $6.8 \times 5.2 \times 4.6 \mathrm{~cm}$ well defined cyst with internal echoes in the right side of neck. The lesion was deep to sternocleidomastoid muscle and right lobe of thyroid. It was medial to common carotid artery. It was displacing the trachea to left side. Neck vessels appeared normal on Color Doppler. MRI showed large well defined mass in the right side of neck with fluid intensity, deep to sternocleidomastoid and posterior to thyroid lobe. The mass was displacing the trachea to left side.

Excision of the cyst in to was done under general anesthesia. Intra operatively cyst was approximately $6 \times 4 \mathrm{~cm}$ in size. The cyst wall was very thin. Cyst was located medial to Sterno-mastoid muscle \& Common carotid artery and posterior to right lobe of thyroid. Specimen was sent for histopathological examination. It was suggestive of Branchial Cyst with the cyst wall being lined by squamous epithelium.

DISCUSSION: Branchial cleft cysts are the most common cystic swellings of the neck. The term branchial cyst was first coined by Ascherson in 1832. ${ }^{[5]}$

Second branchial cleft anomalies are the most common branchial apparatus anomalies, representing approximately $95 \%$ of cases.[1,2] Several theories are proposed its origin.[3] Most accepted theory is the evolution of incomplete branchial apparatus.[6]

Second branchial cleft cysts are also known as lateral cervical cysts. These are usually seen deep to the anterior border of sternocleidomastoid. These are commonly seen at the junction of upper $1 / 3^{\text {rd }} \&$ lower $2 / 3^{\text {rd }}$ of the sternocleidomastoid. 


\section{According to Bailey Second Branchial Cleft Anomalies are divided into:}

- Type I: Localized between the platysma \& anterolateral surface of SCM.

- Type II: Along the anterior surface of SCM, lateral to carotid space \& posterior to submandibular gland.

- Type III: Located between internal carotid and external carotid artery. The presence of tail of the cyst between internal \& external carotid pathognomonic of type III.[7,8]

- Type IV: Originates from pharyngeal mucosa, deep as compared to the palatine tonsils and often it can reach to base of the skull.[8]

The peak age incidence of branchial cysts is in the third decade.[9] Sixty percent are in males \& sixty percent are on the left side. In patients over the age of 40yrs a cystic metastatic node from a primary neoplasm has to be excluded. [10] Other differential diagnosis are Lymphoma, Tuberculosis, carotid body tumor. Ultrasonography is the primary investigation of choice for these types of cystic lesions. The advantage of USG is that it is noninvasive technique which fairly distinguishes various type of cystic neck lesions.

In these types of late presentations, CT/MRI is useful to distinguish between other cystic neck lesions and to avoid complications like injury to carotids, spinal accessory nerve, hypoglossal nerve.

CONCLUSION: Branchial cleft cyst is common in young adults. In elderly it is important to exclude metastatic cystic lymphadenopathy with correct radiological diagnosis like CT/MRI. A proper preoperative assessment of cystic lesion is important to prevent complications while excision.

\section{REFERENCES:}

1. Gold BM (1980) Second branchial claft and fistula. AJR Am J Roentgenol 134: 1067-1069.

2. Coppens F, Peene P, Lemahieu SF (1990) Diagnosis and differential diagnosis of branchial cleft cysts by CT Scan. J Belge Radiol 73: 189 - 196.

3. Watkinson JC, Gilbert RW, editors, Stell and Maran's Text book of Head and Neck Surgery and oncology, 5th edition, London: Hodder Arnold; 2012.

4. Gleeson M, Browning GG, Burton MJ, Clarke R, Hibbert J, Jones NS, et al, editors Scot- Brown's Otorhinolaryngology, Head \& Neck Surgery, 7th edition Great Britain: Hodder Arnold; 2008.

5. Mihaela Mitroi, Management of second branchial cleft anomalies, Romanian Journal of Morphology and Embryology, 2008; 49 (1): 69 - 74.

6. Cho SS Zal Zal GH (MGJ) Branchial anomalies: a review of 52 cases. Laryngoscope 105: 909913.

7. Lev S, Lev MH (2000) Imaging of Cystic lesions: Radiol Clin North Am 38: 1013-1027.

8. Koeller KK, Alamo L, Adair CF (1999) congenital cystic masses of the neck: Radiologic pathologic correlation. Radiographics 19: 121.

9. M.J. McClure, C S Mc Kinstry, R Stewart, M Madden later presentation of branchial cyst. The Ulster Medical Journal, Volume 67, No. 2, PP. 129-131, Nov 1998.

10. Flanagan PM, Roland NJ, Jones AS, Cervical node metastasis presenting with features of branchial cysts. J Laryngol Otol 1994; 108: 1068-71]. 


\section{CASE REPORT}

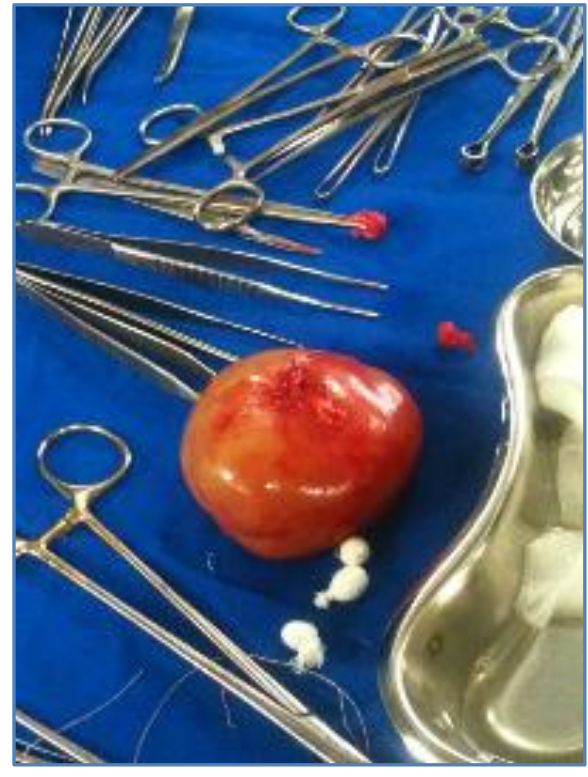

Fig. 1: Excised branchial cyst

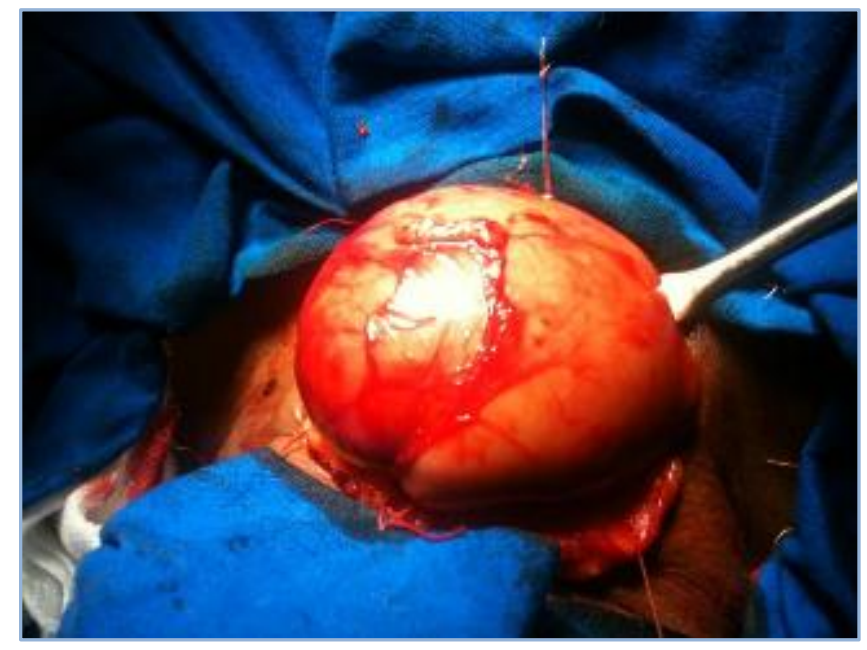

Fig. 2: Intra Operative picture of branchial cyst

\section{AUTHORS:}

1. G. Vinod Kumar

2. B. Ranganatha Reddy

3. Supriya Mohan Bhat

4. Rakesh Vuppala

\section{PARTICULARS OF CONTRIBUTORS:}

1. Assistant Professor, Department of ENT, Apollo Institute of Medical Sciences \& Research.

2. HOD, Department of ENT, Apollo Institute of Medical Sciences \& Research.

3. Assistant Professor, Department of ENT, Apollo Institute of Medical Sciences \& Research.

\section{FINANCIAL OR OTHER}

COMPETING INTERESTS: None
4. Assistant Professor, Department of ENT, Apollo Institute of Medical Sciences \& Research.

\section{NAME ADDRESS EMAIL ID OF THE CORRESPONDING AUTHOR:}

Dr. G. Vinod Kumar,

Plot. No.136, Sardar Patel Colony,

Trimulgherry, Secunderabad-15,

Telangana.

E-mail: drvinnu2004@yahoo.co.in

Date of Submission: 31/08/2015.

Date of Peer Review: 01/09/2015.

Date of Acceptance: 05/09/2015.

Date of Publishing: 10/09/2015. 